\title{
ROLE-REVERSAL: A SOMEWHAT NEGLECTED MIRROR OF HERITAGES OF THE PAST
}

\author{
Franco Borgogno and Massimo Vigna-Taglianti
}

\begin{abstract}
Within a clinical-theoretical framework focused on transference-countertransference dynamics, the authors reflect on role-reversal and on the reasons it has been neglected for a long time in literature. This primitive inter- and intra-psychic process, often at the forefront in our practice, will be discussed in its principal aspects (patient's unconscious identification with parents' psychic culture and concomitant dissociation of the infant part of the self), signaling how the enactment can be an inevitable element which, putting into play the past dissociated object relationships, becomes a source of mutative understanding.
\end{abstract}

KEY WORDS: role-reversal; transference-countertransference dynamics; curative factors; acting cure-talking cure; dissociation; identification with the aggressor.

DOI:10.1057/ajp.2008.31

You see me now, a veteran of a thousand psychic wars, I've been living on the edge so long where the winds of limbo roar. And I'm young enough to look at, and far too old to see; all the scars are on the inside and I'm not sure if there is anything left of me. (Blue Oyster Cult, 1981)

\section{PRIMITIVE TRANSFERENCE, SYMBOLIC TRANSFERENCE, AND REPETITION}

At the heart of our reflections, there is the fact that transference-the elective scene in which the past returns and comes back to life (Freud,

Franco Borgogno, Ph.D., is Professor of Clinical Psychology at the Psychology Faculty of Turin University, Training and Supervising Analyst at the Società Psicoanalitica Italiana (International Psychoanalytical Association), Chair (for Europe) of the IPA Committee "Psychoanalysis and University," and Founding Member of the "Sándor Ferenczi International Foundation."

Massimo Vigna-Taglianti, M.D., is Child Neuropsychiatrist, Full Member of the Società Psicoanalitica Italiana (International Psychoanalytical Association), Lecturer at the School of Specialization in Clinical Psychology at Psychology Faculty of Turin University and Member of the "Associazione Culturale Sándor Ferenczi."

Address correspondence to Franco Borgogno, Ph.D., Via Cavour 46, Torino 10123, Italy; e-mail: borgogno@psych.unito.it or Massimo Vigna-Taglianti, M.D., P.zza Statuto 11, Torino 10122, Italy; e-mail: vignataglianti@fastwebnet.it

"Individual Paper" presented at the EPF Vienna Conference, on March the 15th, 2008. A slightly different version of this paper was published in the Rivista di Psicoanalisi, LIV, 3, 591-603, 2008 with the title "Il rovesciamento dei ruoli: un 'riflesso' dell'eredità del passato piuttosto trascurato." 
1905, 1912)—will manifest itself within our work under different forms, and not always on a symbolic level. For instance, in patients whose psychic suffering originates in the area of preverbal trauma - in the area of the basic fault (Balint, 1968), ${ }^{1}$ we could say-transference occurs mostly at a more primitive level of expression (Winnicott, 1967a,b) that involves in an unconscious way, at least initially, not only just the patient but also the analyst. In such situations, in fact, we are in the domain of non-occurred or non-completed symbolization, that with the passing of time can be slowly reintroduced into the analysis by the functions that the analyst performs, so that the patient will eventually be able to find the symbolization within himself. Therefore, we want to stress here (1) that these functions are aimed to create the affective inter-psychic conditions that will enable the transmission of the emotional alphabet that is needed to master the lived experiences and (2) that in these analyses, we need a long time in order for the minimal psychological conditions for the development of transference to be established, since such a patient is lacking a piece of experience connected to subjectivation (Botella \& Botella, 2001) and, consequently, trauma for them would consist of the very fact that something that should have happened has, actually, not occurred (Ferenczi, 1932b; Winnicott, 1963; Bokanowski, 2004; Borgogno, 2005, 2006).

After this brief theoretical introduction, we would also like to underline that these more archaic forms of the transference-countertransference issue-which frequently set aside verbal contents - take shape in the analytical setting or in its framework through actual mutual enactments. These enactments do involve, in an unconscious manner, the analyst as well (who finds himself experiencing strong emotional feelings) and, if adequately worked through in the long wave of the analytical encounter, will become, with their reiterated re-proposal, what mainly allows us to reach a high degree of knowledge. Precisely this knowledge will be the transformative engine in the analysis and, according to this point of view, our commitment will be of two types. On one hand, it consists in welcoming the patient's repetition as his attempt at giving a solution to a task that was left suspended, with the expectation of finding an "encouragement to feel and to think the traumatically interrupted mental experiences to their very end" (Ferenczi, 26-III-1931, in 1920-1932). On the other hand, the analyst has to offer the patient that very mental activity that can bring back to life and restart what has been left unmetabolized at the level of perception and affective significance. $^{2}$

In addition, in our opinion, these enactments very often happen through the "dissociation within the analyst" of the infantile and suffering part of the patient. In other words, the enactments occur through an inversion of roles and it is precisely the role-reversal on which we will draw and 
concentrate our attention, since little light has been shed on it during the history of psychoanalysis. This could have happened mainly because of the higher price required of the analyst when it is the case of personifying and, literally speaking, "embodying" in vivo, within the unconcious dialog, not only the parents, but also the suffering child in relation, through the patient, to a truly inadequate and traumatic parent. Moreover, it is not at all easy to recognize this issue owing to the main theoretical trend in which we have grown up: a trend that has essentially protected the parents (and consequently ourselves), preventing us from identifying more deeply with the children's needs and reasons. ${ }^{3}$

All we have said leads us to make the following three considerations. The first one is that the analytic mirror is no longer meant to reflect back to the patient, in the most accurate way possible, only his emotional contents; on the contrary it must unfailingly "strive" to become aware of and responsible for that additional part that is necessary for a true psychic and affective validation (in other terms, what it has to refract, in order to make an actual confirmation possible, has to do not so much with our illuminating view of the subject, but rather with something that comes really from our own person; Winnicott, 1967a). The second consideration is that, for this very reason, in order to make the "Werde, was Du bist" possible, at least in the clinical situations that we have in mind while writing this paper, the "construction" to which the analyst is called is indeed the construction of an affective "effective" reality, which is anyway preliminary to the construction of a real memory (Wirklichkeitsgefühl). The kind of construction we are referring to is-to be more precise-a little different and surely more complex than the more cognitive operation that Freud introduced towards the end of his life when, aiming to stress the very effects of narcissistic traumas that overwhelmed the common neurotic defense mechanisms, he spoke of "constructions in analysis" (Freud, 1937). In brief, unlike Freud, we believe that the recovering of a historical past not symbolized and inaccessible (inaccessible through the usual recollections on which the analysis hinges) requires much more work on our part. We call this work "dirty" because in these circumstances, in order to later emerge differentiated and capable of thought, we need to have been previously involved and not fear being and showing ourselves "mishmashed" and "mestizo" (Borgogno, 1999) in the dynamics of transference and countertransference, and moreover not to be seduced by our wish to "unplug" (Vigna-Taglianti, 1999, 2002). The third consideration is that of course the analytic working through the countertransference response to what the patient continuously and repeatedly asks us to receive and contain in his/her place is very consistent and surely not achievable at once. 


\section{ROLE-REVERSAL: CLINICAL PHENOMENOLOGY AND HISTORY OF CONCEPT}

Addressing now the dissociation of the patient's infantile self into the analyst and to the resulting role-reversal (in this case, the patient is in fact unconsciously identified with the caregivers and with their psychic culture), before sketching two clinical vignettes in order to illustrate our thinking, we want to point to some general features of this inter- and intra-psychic dynamic that often occurs in analyses and to stress, however swiftly, the pioneering work of Ferenczi about this issue, as well as the work of those who recovered its "shadow," even without being necessarily aware of having inherited his theoretical trend.

Concerning the duration, fixity, and pervasiveness with which this typical (for us) constellation of "enactment" (Jacobs, 1991; Ogden, 1994, 2001; Renik, 1997; Smith, 1993; Bromberg, 1998/2001) takes place in the analytical dialog and interaction, experience teaches us that -in the treatment of children and adults alike-the temporal dimension of role-reversal usually takes on, to stay within the theatrical metaphor, two opposite forms: either a "one-off" show or a "two-hundredth rerun" one. In general terms, one can sustain that the more fixity and duration of prompt-copies are consistent and rigid, the more the psychic disorder at its root is considerable. Yet, we must not neglect the fact that episodic, rough, and restricted acting, as well, could be the sign of an area of severe and unknown suffering, which should be taken into the most serious account (e.g., with adolescents, though not only with them). After this preamble, the protracted repetition of the same "show" could be linked, on one hand, to a deficit of the analyst's understanding, while, on the other, it frequently corresponds to the patient's deep need to investigate closely and concretely how the mind of the other can manage the suffering that affected him, becoming a container of vicissitudes that the patient, until then, could not speak about or think of. ${ }^{4}$ This particularly occurs when we are facing histories marked by preverbal traumatic events that have created such damage to the structuring of the ego that the patient's dramatic nature can no longer be "dramatized" and, instead of anxieties, a catastrophic terror has settled in.

Apart from the extreme situations we have just shown in which the ego and the symbolization process are evidently compromised, in child psychoanalysis the role-reversal and dissociation of self are almost a natural event. ${ }^{5}$ Through playing and dramatizing, the child aims, as we know, to actively play out what he has passively endured, and to use such relational strategies as a physiological part of his identifying road. Nevertheless, even the child analysis room - an ideal gymnasium and laboratory for studying these phenomena in normality - can sometimes turn into a place where we become spectators and actors of obscure and disturbing role-reversals 
that have almost entirely lost their "game-like guise," as often occurs in adults' analysis room. These are precisely the situations in which the analyst, along with his hard work of decoding and "interpreting" the dissociated feelings and roles, will have to provide-and to give existence to-those parental functions and those aspects of the infantile self that have been omitted and are lacking in the patient's history. In other words, the analyst will have to be both, and at the same time, the suffering and inadequate parent the patient has had, and a parent different from the one fate provided him with. Moreover, the analyst will also have to be both the child that the patient was, and the child who is able to feel, to react, and also to make himself heard: the very child the patient has never been and known in his childhood and adolescence. ${ }^{6}$

Now, before introducing two patients of ours, we would like to single out some of the historical roots of this theoretical-clinical view which we want to point out here. First, we must mention Sándor Ferenczi who, since the very beginning of psychoanalysis, perceived and denounced a certain phobia of analysts as to feelings and, in particular, to identification with the suffering child and his vulnerability. A phobia, by the way, which would even give rise to what he has called "terrorism of suffering" ${ }^{7}$ and which probably prevented us from explicitly recognizing the importance of rolereversal in our work (one of the reasons, in our opinion, for the scarcity of contributions to our literature on this topic). Such a phobia could have prevented this kind of dynamic from taking shape (and body) in the therapeutic relationship, and therefore would have compelled us to reproduce the conduct of the omissive and depriving parents that not infrequently have been at the very source of these patients' psychic grief.

As to Ferenczi, we want to recall (a) his extreme capability, from the first years of his analytical journey, to grasp and recognize how often the analyst finds himself experiencing in his own skin the way in which patients (adults and children as well) felt treated by "grown ups," both in their past and in the reality of the present (Ferenczi, 1912) and (b) the troubled workingthrough he encountered at the end of his life-see RN case (Ferenczi, $1932 a, b)^{8}$ - of his own difficulties in identifying with the inadequate parent and, even more, with the child intruded on and spoiled by the aggressive and completely inappropriate adult. Although such difficulties did not lead him to formulate a proper theory based on role-reversal, they permitted him, in such early times, to visualize how the intra-psychic can relive within the inter-psychic, becoming a masterly key for recognition and transformation of traumatic and traumatizing past events.

As regards, authors who delved into and explored this clinical-theoretical breach opened by Ferenczi-besides naming Helene Deutsch (1926), Anna Freud (1936), Racker (1948-1958), and Searles (1947-1948, 1959) for their 
contributions more generally connected with identificatory processes-we will only mention those who helped us in expressing the thoughts that we have put forward: Paula Heimann $(1965,1975)$ for having underlined the fact that, if trauma is present in the patient's history, the analyst can "unconsciously introject $[. .$.$] the patient, who at this point acts on the basis of an$ identification with a rejecting, intrusive maternal figure, and repeats their personal experience by role-reversing"; Masud Khan (1974) for his detailed case study of Peter in which he outlined the fate of role-reversal in analysis, as well as the analyst's capacity to experience this situation, temporarily losing his own subjectivity and returning, only in a second moment, to the patient with a deep reworking-through of those painful pathogenic emotional states that the patient was not able to express and to communicate through words; Pearl King (1951/1953/2004, 1962, 1978) for her whole life's analytical research on this typical affective response of the analyst to the patient's communications, focused since her first published paper on Philip, a little boy aged 4 coping with the death of his brother at age 2 and with his mother's depression-withdrawal; Joseph Sandler $(1976,1985)$, especially for his notes on role resonance and on the complex system of unconscious communications (both issued and received communications, as they operate within the analytical couple, when each partner attempts to impose on the other a specific intra-psychic role relationship), but also for his reflections together with Anna Freud on the distinctions among externalization, projection and reversal of roles, as well as among realization, acting out, successful defense and sublimation. Peter Giovacchini (1989) for his acute description of the re-creation of the infantile traumatic environment in the transference-countertransference interaction with patients who suffer from primitive mental disorders; among more recent authors-René Roussillon (1991, 1999), who theorized, leaning on Anzieu's concept of "paradoxical transfer-

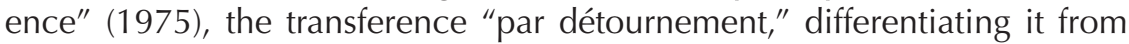
the more classic "par déplacement"; and Philip M. Bromberg (1998/2001) for his deep exploration into the process of enactment and dissociation.

\section{WORKING WITHIN THE ROLE-REVERSAL AREA}

Here are two patients of ours who have inspired our thoughts. Unfortunately, we have to condense all the complex history of their analyses and our work on the role-reversal dynamics with a few brush-strokes.

Mara, a young schizoid university student, very silent and affectively dull, asked the analyst more than 4 years ago to "concretely become a person who had to literally interpret," in complete silence on her part (a silence sporadically broken by moans and groans related to vague, tormenting, and painful bodily sensations). By the way, this characteristic 
was already present in the dream she brought to her first interview: a character, unable to speak, who against its own will had to repeatedly witness the harakiri and consequent agony of another character, who was also of uncertain identity, probably Japanese, and mute. This was the dream: "A Japanese person of uncertain identity was committing harakiri in a cloister and wanted me to see it. So I started to run but this person followed me and periodically caught up with me, 'arch after arch,' collapsing on the floor with the intestines coming out. I was horrified and disgusted."

By doing so, the patient led the analyst to embody an undesired and incompetent little child (but also a "wise baby") who could not be of any help to the ill and complaining mother: a child who did not know and did not speak her parents' language and who could not even be alive, because life for her parents was only equivalent to loss, death and grief. In this case, it was the analyst, who (a) again and again had to put on, one by one, the feelings of baby-Mara towards a fragile and cumbersome mother who suffered from mysterious somatic symptoms and a mysterious pain of which nobody in the family spoke (the pain was also due to the fact that in her family all the fathers had died exactly at the time of the birth of their children) and towards a father who was also withdrawn and depressed and who (b) only at a certain point, after having helped the patient to reintegrate many threads of her history - through risking a professional harakiri-had to claim with vehemence his own right to existence and to trigger with this new act of expression the very "Risorgimento" of the patient (Borgogno, 2004). This happened with the bursting out of a participate sequence of interpretations in a session.

In other words, in this analysis (something that one of us described in previously published papers) the analyst had to be both, and at the same time, the Mara-child that the patient was and the Mara-child that she was not allowed to be in her infancy (i.e., a child who is able to feel, to react and also to make herself heard: the very child that the patient has never been, nor known in her childhood and adolescence). Furthermore, the analyst had to be the suffering and inadequate mother and father that Mara had had, and also a kind of parent different from the ones that she was provided by her fate.

Alberto arrived in analysis because of a hardened discontent in his relationships with women and for a strong feeling of estrangement towards life. He pressed his analyst to disentangle an intricate knot of paranoid anxieties, by regarding the sessions as a medical drug (a "purge" or an "enema") with the aim of "making him feel better" and compelling him to a forced production of verbal contents. Although it was quite easy to reconnect such a persecution to an alarming "ghost" of a father-head master (who was both demanding and intrusive, and who suddenly passed away when Alberto 
was only 10 years old), it proved a much more arduous task to find a meaning to the patient's polite but unceasing affirmation that he was not cut out for what they were doing together (a statement, which, however, he frequently contradicted by the regularity with which he arrived at his appointments). Alberto actually asked the analyst to become aware of how much he had been affected by his relationship with his mother, a parsimonious woman both in emotions and dynamism, who, as a widow, never expressed anything but duty and sacrifice in raising and looking after her five children. He also asked the analyst to be the one to start to contrast the stagnant and dull atmosphere and the impending threat of interruption that overshadowed the sessions. There was a turning point when the analyst repeatedly made his patient notice a paradox: contrary to what his internal mother-with whom he was identified — sustained (i.e., that Alberto was not at all interested in what was emerging from analysis), he continued to do his very best to re-create "his home air." He did this with the very aim that "somebody" could understand what it had meant for him to be perpetually exposed to resignation and lack of desire.

In this analysis, understanding and "interpreting" the role-reversal that was taking place in the sessions needed a careful and progressive workingthrough of the analyst's countertransference. At first, in fact, he sympathized with Alberto, who perceived him as a threatening and persecutory object connected with his father's imago. Later on, however, the analyst started to feel a vague uncertainty and discomfort, and still later an unpleasant irritation due to Alberto's subtle disdain and continuous aloofness. Finally, he experienced a deep sense of failure connected with his feeling useless, rejected and refused. These were at last decoded as signals of "role-reversal," in which the analyst was identified with the dissociated infantile part of the patient, leaving to the latter the possibility of "playing" the role of his scarcely vital and nihilist narcissistic mother.

\section{A FINAL REMARK}

To close, today-stronger and better equipped in our devotion to the psychoanalytical method-we believe that an authentic talking cure is not possible without an "inter-acting cure." Action can just be, sometimes, a matrix of fertile thought for a fruitful working-through and psychic transformation. Definitively, it takes a lot of committed, unselfish work, of a modest and humble nature, to reach the mutative interpretation, and, above all being available to momentarily abandoning our role in order to take on-as interpreters-the unconscious roles the patient asks us to play. In our opinion, following what we have so far stressed, we would suggest that one of Freud's (1914) most precious heritages could be rewritten in the 


\author{
following sequence: "Experiencing (making ourselves 'interpreters'), \\ repeating, working/re-working-through and remembering," with much \\ emphasis on "experiencing (making ourselves 'interpreters')" and "repeating" \\ as basic conditions for "working/re-working-through" and "remembering," \\ or better, "thinking."
}

\title{
NOTES
}

1. Balint (1968) is the author who, working in this clinical field, raised the problem of "what language for which patient" to the psychoanalytical community of his time, a problem that in those years - as his letters testify — did not leave indifferent even Winnicott (Rodman, 1987). Going backwards in time, this problem was openly addressed by Ferenczi with his reflections on the "confusion of tongues" (1932a). This confusion did not exclusively regard the communicational interactions between parents and children, but also those between analysts and patients.

2. A point of view adopted by Lagache (1952), when he compares transference to the "Zeigarnik effect," without, however, explicitly mentioning Ferenczi.

3. With regard to this, Ferenczi's considerations about identification with the aggressor $(1932 a, b)$ are today particularly interesting. According to him, this complex inter- and intra-psychic dynamic springs out not only in particularly disturbed and depriving environmental conditions, but also in normality, leading to possible identificatory collusions both with the "aggressor" and with the "victim" (Frankel, 2002).

4. In his Clinical Diary (1932) Ferenczi clearly describes, in the case of the "patient who wanted him to become Julius Caesar," the analyst's need to cohabit with the patient's experience of pain (to "take it onto himself": "seize her," as Ferenczi writes), in order to give it a meaning in a way that can be really convincing for the patient. This is precisely what Bion suggests, many years later, in Cogitations (1992).

5. Classic examples of this are situations in which the child becomes with the analyst a severe teacher who scolds and pesters a clumsy student, the assertive manager father who is absent-minded of the affective and playing demands of the child, the affectionate mother who cuddles her baby, or the wolf who is leader of the pack and teaches his little cub how to find its bearings in the forest.

6. The subject who in part is deprived of his own self is not aware of what he is really missing, in the same way that his parents - when he was a child - were not aware of what they were making the child lack and of what was absent in their inappropriate taking care of the needs and requests of the child. At worst, these persons, despite feeling an intense uneasiness (which they find in some way obscure), do not know that they have been deprived: they can only discover this in analysis when they obtain, through "experiencing it," a psychic environment different from the one they grew up in, recovering at the same time within themselves those resources they had never imagined they could have.

7. With this term, Ferenczi describes a kind of implicit or explicit message, very recurrent, in his opinion, in the process of growth and in analysis, when the parent as well as the analyst meta-communicate to the child and to the patient that they, with their own needs and conducts, want their parents and their analysts to fall ill or even to die.

8. It was exactly with RN-alias Elizabeth Severn-that Ferenczi came to realize that she was unconsciously identified with her abusing and depriving mother and father, and that he had turned, in the relationship with her, into the little girl that the patient had dissociated from herself. Ferenczi at first could not bear to undertake the role RN asked him to assume, as he himself was not able to contain and consider the painful experience related 
to being in a relationship with parents who threaten their children with "terrorism of suffering" (Ferenczi, 1929, 1932a, b), since he had already directly experienced it in his childhood with his own mother.

\section{REFERENCES}

Anzieu, D. (1975). Le transfert paradoxal. De la communication paradoxale à la reaction thérapeutique negative. Nouvelle Revue de Psychanalyse, 12, 49-72.

Balint, M. (1968). The basic fault: Therapeutic aspects of regression. London: Tavistock.

Bion, W.R. (1992). Cogitations F. Bion (Ed.), London: Karnac Books.

Blue Oyster Cult (1981). Veterans of psychic wars. In Fire of unknown origin, Columbia Records.

Bokanowski, T. (2004). Variations on the concept of traumatism: Traumatism, traumatic, trauma. International Journal of Psycho-Analysis, 86, 251-265, 2005.

Borgogno, F. (1999). Psychoanalysis as a journey. London: Open Gate Press, 2007.

Borgogno, F. (2004). On the patient's becoming an individual: The importance of the analyst's personal response to a deprived patient and her dreams. Psychoanalytic Dialogues, 14(4), 475-502.

Borgogno, F. (2005). Ferenczi's clinical and theoretical conception of trauma: A brief introductory map. American Journal of Psychoanalysis, 67(2), 141-149, 2007.

Borgogno, F. (2006). Ferenczi and Winnicott: Searching for a "missing link" (of the soul). American Journal of Psychoanalysis, 67, 221-234, 2007.

Botella, C. \& Botella, S. (2001). The work of psychic figurability: Mental states without representation. Hove and New York: Brunner-Routledge, 2005.

Bromberg, P.M. (1998/2001). Standing in the spaces. Essays on clinical process, trauma, and dissociation. Hillsdale, NJ: The Analytic Press.

Deutsch, H. (1926). Occult process occurring during psychoanalysis. In G. Devereux (Ed.), Psychoanalysis and the occult. New York: International University Press, 1953.

Ferenczi, S. (1912). On transitory symptom-constructions during the analysis. In E. Jones (Ed.), First contributions to psychoanalysis (pp. 193-212), London: Karnac Books, 1952.

Ferenczi, S. (1920-1932). Notes and fragments. In M. Balint (Ed.), Final contributions to the problems and methods of psycho-analysis (pp. 216-279), London: Karnac Books, 1955.

Ferenczi, S. (1929). The principles of relaxation and neocatharsis. In M. Balint (Ed.), Final contributions to the problems and methods of psycho-analysis (pp. 108125), London: Karnac Books, 1955.

Ferenczi, S. (1932a). Confusion of tongues between adults and the child. In M. Balint (Ed.), Final contributions to the problems and methods of psycho-analysis (pp. 156-167), London: Karnac Books, 1955.

Ferenczi, S. (1932b). The clinical diary. In J. Dupont (Ed.), Cambridge, MA: Harvard University Press, 1988.

Frankel, J. (2002). Exploring Ferenczi's concept of identification with the aggressor: Its role in trauma, everyday life, and the therapeutic relationship. Psychoanal. Dial, 12(1), 101-139. 
Freud, A. (Ed.) (1936). The ego and the mechanism of defence. The writings of Anna Freud, (Vol. II), New York: International Universities Press, 1966.

Freud, S. (1905). Fragment of an analysis of a case of hysteria. Standard Edition, 7, $1-122$.

Freud, S. (1912). The dynamics of transference. Standard Edition, 12, 97-108.

Freud, S. (1914). Remembering, repeating and working-through. Standard Edition, $12,145-156$.

Freud, S. (1937). Constructions in analysis. Standard Edition, 23, 255-269.

Giovacchini, P.L. (1989). Countertransference: Triumphs and catastrophes. New York: Jason Aronson.

Heimann, P. (1965). Comment on Dr. Kernberg's paper on "Structural derivatives on object relationships". In P. Heimann (Ed.), Children and children-no-longer. Collected papers 1942-1980. London: Tavistock-Routledge, 1989.

Heimann, P. (1975). From "cumulative trauma" to the privacy of the self. A critical review of M. Masud R. Khan's book. International Journal of Psycho-Analysis, $56,475-476$.

Jacobs, T. (1991). The use of the self. Madison, CT: International University Press.

Khan, M.M.R. (1974). The privacy of the self. London: Hogarth Press.

King, P. (1951/1953/2004). Change: The psychoanalysis of a four-year-old boy and its follow-up. In P. King (Ed.), Time present and time past. London: Karnac, 2005.

King, P. (1962). The curative factors in psychoanalysis. In P. King (Ed.), Time present and time past. London: Karnac, 2005.

King, P. (1978). Affective response of the analyst to the patient's communication. In P. King (Ed.), Time present and time past. London: Karnac, 2005.

Lagache, D. (1952). Le problème du transfert. In D. Lagache (Ed.), Oeuvres III, 1952-1956, Paris: Presses Universitaires de France, 1980.

Ogden, T.H. (1994). The analytical third: Working with intersubjective clinical facts. International Journal of Psycho-Analysis, 75, 3-20.

Ogden, T.H. (2001). Conversations at the frontier of dreaming. Northvale, NJ and London: Jason Aronson.

Racker, H. (1948-1958). Transference and countertransference. New York: International University Press, 1968.

Renik, O. (1997). Conscious and unconscious use of the self. Psychoanalytic Inquiry, 17, 5-12.

Rodman, F.R. (Ed.) (1987). The spontaneous gesture. Selected letters of D. W. Winnicott. Cambridge, MA: Harvard University Press.

Roussillon, R. (1991). Paradoxes et situations limites de la psychanalyse. Paris: PUF.

Roussillon, R. (1999). Agonie, clivage et symbolization. Paris: PUF.

Sandler, J. (1976). Countertransference and role-responsiveness. International Review of Psycho-Analysis, 3, 43-47.

Sandler, J. (1985). The analysis of defence. The ego and the mechanisms of defence by Anna Freud revisited. New York: International Universities Press.

Searles, H.F. (1947-1948). Concerning transference and countertransference. International Journal of Psychoanalytic Psychotherapy, 7, 165-188, 1979.

Searles, H.F. (Ed.) (1959). The effort to drive the other person crazy-An element in the aetiology and psychotherapy of schizophrenia. Collected papers on schizophrenia and related subjects. London: The Hogarth Press and the Institute of Psychoanalysis, 1965. 


\section{BORGOGNO AND VIGNA-TAGLIANTI}

Smith, H.F. (1993). Engagements in the analytic work. Psychoanalytic Inquiry, 13, 425-454.

Vigna-Taglianti, M. (1999). Interpret-agiti o interpret-azioni? Quaderni di Psicoterapia Infantile, 39, 167-183.

Vigna-Taglianti, M. (2002). Transfert regressivo e transfert persecutorio: Trasformazioni del Sé e funzioni analitiche. In F. Borgogno (Ed.), Ferenczi oggi. Torino: Bollati Boringhieri, 2004.

Winnicott, D.W.W. (1963). Fear of breakdown. In C. Winnicott, R. Sheperd \& M. Davis (Eds.), Psycho-analytic explorations. London: Karnac Books, 1989.

Winnicott, D.W.W. (Ed.) (1967a). Mirror-role of mother and family in child development. Playing and reality. London: Tavistock, 1971.

Winnicott, D.W.W. (1967b). Postscript: D. W. W. on D. W. W. In C. Winnicott, R. Sheperd \& M. Davis (Eds.), Psycho-analytic explorations. London: Karnac Books, 1989. 